\title{
Loranthus pulverulentus: A Potent Source of Natural Antioxidants and Alternative Medicine
}

\author{
Muhammad Asam Raza, ${ }^{1,2}$ Rukhsana Kausar, ${ }^{2}$ Faraz Ali Rana, ${ }^{2}$ Muhammad Danish, \\ Durre Shahwar, ${ }^{2}$ and Farwa Anwar ${ }^{1}$ \\ ${ }^{1}$ Center of Natural Product, Department of Chemistry, Hafiz Hayat Campus, University of Gujrat, Gujrat 50700, Pakistan \\ ${ }^{2}$ Research Laboratory II, Department of Chemistry, Government College University, Lahore 54000, Pakistan \\ Correspondence should be addressed to Muhammad Asam Raza; asamgcu@yahoo.com
}

Received 24 May 2013; Revised 5 September 2013; Accepted 6 September 2013

Academic Editor: Iciar Astiasaran

Copyright (C) 2013 Muhammad Asam Raza et al. This is an open access article distributed under the Creative Commons Attribution License, which permits unrestricted use, distribution, and reproduction in any medium, provided the original work is properly cited.

\begin{abstract}
This study was designed to evaluate the antioxidant potential of Loranthus pulverulentus. Stem bark, leaves, and seeds of Loranthus pulverulentus were extracted in methanol:water $(90: 10)$ and partitioned with $\mathrm{n}$-hexane, chloroform, ethyl acetate, and n-butanol successively using partition chromatography. Total phenolic contents and antioxidant potential were checked using standard protocols. Total phenolic contents of all extracts were determined, using Folin-Ciocalteu reagent, and ranged between $151 \pm 2.1$ and $396 \pm 1.6$ for stem bark, $137 \pm 0.9$ and $430 \pm 2.2$ for, and $39 \pm 0.6$ and $231 \pm 1.7$ for seeds. The antioxidant potential of extracts was evaluated; namely, DPPH, FRAP, and total antioxidant models. The ethyl acetate extract of stem-bark, leaves, and seeds showed the highest activity in DPPH $\left(94.5 \pm 2.1 \%, 96.30 \pm 0.9 \%\right.$, and $92.30 \pm 1.1 \%, \mathrm{IC}_{50} 15.9 \pm 0.5 \mu \mathrm{g}, 14.5 \pm 0.8$, and 102.7 \pm 1.3 , resp. $)$, FRAP $(7.7 \pm 0.6,7.5 \pm 0.7$ and $6.6 \pm 0.7$, resp.), and total antioxidant $(0.95 \pm 0.09,1.19 \pm 0.09$, and $0.686 \pm 0.08$, resp.). Strong correlations were observed between total phenols versus total antioxidant activity, DPPH, and FRAP with $R^{2}$ values ranging from 0.8185 to 0.9951 (stem-bark), 0.6728 to 0.8648 (leaves), and 0.8658 to 0.9910 (seed) which indicated that phenolic contents are the major constituents responsible for antioxidant activity.
\end{abstract}

\section{Introduction}

Plants are important for a healthier life, because they offer us medicines, which are safe, effective and cause no side effects. They play a fundamental role in our lives mainly due to their unusual collection of diverse classes of biochemicals with a variety of biological activities [1,2]. Many medicinal plants contain antioxidants such as polyphenols, which can play an important role in capturing and neutralizing free radicals and quenching singlet and triplet oxygen. Many of these phytochemicals possess significant antioxidant capacities that are associated with lower occurrence and lower mortality rates of several human diseases [3].

Antioxidants are substances which counteract free radicals and prevent the damage caused by them. These can greatly reduce the adverse damage caused by oxidants by crumbling them before they react with biologic targets, preventing chain reactions, or preventing the activation of oxygen to highly reactive products [4]. The use of natural antioxidants for the treatment of free radical induced pathologies has certain advantages, because these agents produce no side effects, possess low toxicity, and effectively act upon the main factors damaging the vascular system. Plants are known to be rich in biologically active substances (flavonoids, phenolic acids, anthocyanins, ethereal oils, tannins, etc.), many of which exhibit antioxidant activity. In recent years, there has been considerable interest in these biologically active substances, methods of their isolation, and evaluation of activity in natural media. Various nutritional biologically active additives and drug preparations aimed at stimulating metabolic processes in the organism have been created based on plant extracts.

Family Loranthaceae consists of about 74 genera, commonly known as mistletoes and mostly distributed in tropics, and semiparasitic shrubs attached to the hosts by modified roots [5]. The leaves and stem bark of some members of this family have been widely used in traditional medicine as therapeutic herbs [6]. Loranthus pulverulentus is a shrub, 
commonly called Parwikh and Grunu in Mirpur, Azad Kashmir. L. pulverulentus is parasitic on Dalbergia sissoo Roxb and Mallotus philippinensis Muell. Leaves juice is used for treating diabetes while its plant extract has wound healing properties. This plant is also used to treat other liver diseases, bacterial infections, and hypertension [7].

Pakistan has a strong tradition of herbal remedies, and like most developing countries, its rural population still depends mainly on the indigenous system of medicine for their health-related matters [8]. The present study was undertaken to explore the antioxidant potential of different parts of $L$. pulverulentus.

\section{Materials and Methods}

2.1. Chemicals and Reagents. Folin-Ciocalteu reagent, 2,2diphenyl-1-picrylhydrazyl(DPPH), FRAP, and gallic acid were purchased from Sigma-Aldrich (USA). All other chemicals and reagents of analytical grade were purchased from Merck (Germany).

2.2. Plant Material. Loranthus pulverulentus was collected from Azad Kashmir Valley, Pakistan, and was identified by Dr. Zaheer-ud-Din Khan where a voucher specimen was deposited at Sultan Herbarium, Department of Botany, GC University, Lahore, Pakistan.

2.3. Extraction. Stem bark, leaves, and seeds were shadedried, powdered, and extracted by soaking in methanol:water $(90: 10)$ at room temperature $(300 \mathrm{gm}$ each). The crude extract was filtered through Whatman filter paper number 40 , concentrated using rotary evaporator at reduced pressure, and partitioned with $\mathrm{n}$-hexane, chloroform, ethyl acetate, and n-butanol.

2.4. Determination of Total Phenolics. Folin-Ciocalteu reagent was used to determine total phenolics in the plant extracts [9]. $300 \mu \mathrm{L}(1 \mathrm{mg} / \mathrm{mL})$ of each sample was mixed with $200 \mu \mathrm{L}$ of Folin-Ciocalteu reagent and $0.8 \mathrm{~mL}$ of $10 \%$ sodium carbonate solution. The mixture was allowed to stand for 30 minutes, and the absorbance was measured at $765 \mathrm{~nm}$ against a blank which contained $300 \mu \mathrm{L}$ of methanol in place of sample. The total phenolic contents were expressed as mg gallic acid equivalents/g of extract. Correlation studies between total phenolic content and antioxidant activities in the DPPH, FRAP, and phosphomolybdate assays were also performed.

2.5. DPPH Radical Scavenging Assay. The radical scavenging ability of different extracts was measured using the method of Shahwar et al. 2010 [9]. Methanolic solution ( $0.2 \mathrm{~mL})$ of all extracts at various concentrations $(25-300 \mu \mathrm{g} / \mathrm{mL})$ was added to $\mathrm{DPPH}(0.025 \mathrm{~g} / \mathrm{L})$ and kept in the dark for 30 minutes at room temperature. The absorbance was measured at $517 \mathrm{~nm}$ using UV/VIS spectrophotometer. The \% scavenging of radical was determined by the following formula:

\%age DPPH inhibition

$$
=\frac{\text { Abs. of blank }- \text { Abs. of sample }}{\text { Abs. of blank }} \times 100 \text {. }
$$

2.6. Ferric Reducing Antioxidant Power. Ferric reducing antioxidant power (FRAP) of the extracts was carried out using the method of Shahwar et al. 2010 [10]. $150 \mu \mathrm{L}$ of FRAP (Fe $\mathrm{Fe}^{\mathrm{III}}$ TPTZ) reagent and different concentrations $(50-200 \mu \mathrm{g} / \mathrm{mL})$ of samples were mixed. Read the absorbance at $592 \mathrm{~nm}$ after 8 min of the addition of reagent.

2.7. Total Antioxidant Capacity by Phosphomolybdate Method. The total antioxidant capacity of the plant extracts was evaluated by the method of Shahwar et al. 2010 [10]. An aliquot of $0.2 \mathrm{~mL}(500 \mu \mathrm{g} / \mathrm{mL})$ of the sample solution was mixed with $2.0 \mathrm{~mL}$ of the reagent solution $(600 \mathrm{mM}$ sulfuric acid, $28 \mathrm{mM}$ sodium phosphate, and $4 \mathrm{mM}$ ammonium molybdate). The reaction mixture was heated at $95^{\circ} \mathrm{C}$ for $60 \mathrm{~min}$, and absorbance was measured at $695 \mathrm{~nm}$ against a blank containing $2 \mathrm{~mL}$ of reagent solution.

2.8. Statistical Analysis. All assays were carried out in triplet form, and standard deviation $( \pm S D)$ was calculated using computer program MS Excel.

\section{Results and Discussion}

Loranthus pulverulentus was collected from Azad Kashmir. The stem bark, leaves, and seeds were separated, shadedried, powdered, extracted with methanol:water (9:1), and partitioned successively with n-hexane, chloroform, ethyl acetate, and n-butanol. All the extracts were evaluated for antioxidant potential through various models, and the results are shown in Table 1 and Figures 1-3.

3.1. Total Phenolic Contents. Total phenolic contents in the plant extract of different parts of the plant were calculated using FC method and expressed as mg gallic acid equivalents/ $\mathrm{g}$ of extract. Our results showed that L. pulverulentus has a high amount of total phenols in stem bark $(151 \pm 2.1$ to $396 \pm 1.6 \mathrm{GAE} / \mathrm{g}$ of extract) and leaves $(137 \pm 0.9$ to $430 \pm 2.2 \mathrm{GAE} / \mathrm{g}$ of extract), while the total phenols of seed extract ranged from $39 \pm 0.6$ to $231 \pm 1.7 \mathrm{GAE} / \mathrm{g}$ of extract. Among the various solvent extracts of bark, leaves, and seeds, ethyl acetate extract of stem bark leaves and seed extracts contained the highest contents of phenols, while n-hexane and aqueous extract of these parts showed less quantity of phenolics (Table 1). Phenolic compounds occur in plants in a large quantity and exert a number of activities; one of them is antioxidant activity. They act as antioxidants through various mechanisms such as hydrogen donors and singlet oxygen quenchers [11].

3.2. Antioxidant Activities. Radical scavenging activities are very important due to the deleterious role of free radicals in foods and in biological systems. Diverse methods are currently used to assess the antioxidant activity of plant phenolic compounds. Chemical assays are based on the ability to scavenge synthetic free radicals, using a variety of radical-generating systems and methods for detection of the oxidation endpoint. $\mathrm{ABTS}^{+}$or DPPH radical scavenging methods are common spectrophotometric procedures for determining the 
TABLE 1: Total phenolic contents and antioxidant activities of aerial parts of L. pulverulentus.

\begin{tabular}{|c|c|c|c|c|c|c|}
\hline Parts & Extract & Total phenols $^{\mathrm{a}}$ & DPPH (\%) & $\mathrm{IC}_{50}(\mu \mathrm{g})$ & $\operatorname{FRAP}^{\mathrm{b}}(\mu \mathrm{M})$ & Total antioxidant $\mathrm{t}^{\mathrm{b}}$ \\
\hline \multirow{6}{*}{ Stem-bark } & LBM & $302 \pm 1.1$ & $83.24 \pm 1.4$ & $68.2 \pm 0.9$ & $6.5 \pm 0.4$ & $0.677 \pm 0.05$ \\
\hline & $\mathrm{LBH}$ & $165 \pm 0.9$ & $55.49 \pm 1.6$ & $32.5 \pm 0.6$ & $4.1 \pm 0.5$ & $0.595 \pm 0.06$ \\
\hline & LBC & $309 \pm 1.5$ & $88.04 \pm 0.7$ & $22.1 \pm 0.5$ & $6.5 \pm 0.9$ & $0.750 \pm 0.04$ \\
\hline & LBE & $396 \pm 1.6$ & $94.50 \pm 2.1$ & $15.9 \pm 0.5$ & $7.7 \pm 0.6$ & $0.952 \pm 0.09$ \\
\hline & LBB & $344 \pm 0.8$ & $91.22 \pm 1.5$ & $17.4 \pm 1.1$ & $6.9 \pm 0.4$ & $0.717 \pm 0.08$ \\
\hline & LBA & $151 \pm 2.1$ & $45.30 \pm 0.6$ & $46.3 \pm 1.8$ & $4.0 \pm 0.2$ & $0.365 \pm 0.03$ \\
\hline \multirow{6}{*}{ Leave } & LLM & $264 \pm 1.3$ & $95.50 \pm 1.1$ & $16.6 \pm 0.7$ & $7.2 \pm 0.8$ & $0.886 \pm 0.08$ \\
\hline & LLH & $137 \pm 0.9$ & $94.30 \pm 0.7$ & $20.2 \pm 1.0$ & $4.2 \pm 0.4$ & $0.603 \pm 0.05$ \\
\hline & LLC & $210 \pm 1.4$ & $95.40 \pm 1.8$ & $32.7 \pm 1.4$ & $6.1 \pm 0.3$ & $0.818 \pm 0.07$ \\
\hline & LLE & $430 \pm 2.2$ & $96.30 \pm 0.9$ & $14.5 \pm 0.8$ & $7.5 \pm 0.7$ & $1.190 \pm 0.09$ \\
\hline & LLB & $278 \pm 1.6$ & $95.10 \pm 1.3$ & $14.8 \pm 0.5$ & $7.3 \pm 0.6$ & $0.780 \pm 0.04$ \\
\hline & LLA & $197 \pm 0.7$ & $94.90 \pm 1.4$ & $18.5 \pm 0.4$ & $6.1 \pm 0.5$ & $0.579 \pm 0.04$ \\
\hline \multirow{6}{*}{ Seed } & LSM & $81 \pm 1.5$ & $49.60 \pm 0.7$ & $201.3 \pm 1.1$ & $2.4 \pm 0.8$ & $0.403 \pm 0.05$ \\
\hline & LSH & $62 \pm 0.6$ & $10.40 \pm 0.5$ & $455.8 \pm 0.9$ & $2.3 \pm 0.5$ & $0.354 \pm 0.02$ \\
\hline & LSC & $179 \pm 1.1$ & $85.00 \pm 0.8$ & $117.5 \pm 0.9$ & $5.3 \pm 0.8$ & $0.651 \pm 0.08$ \\
\hline & LSE & $231 \pm 1.7$ & $92.30 \pm 1.1$ & $102.7 \pm 1.3$ & $6.6 \pm 0.7$ & $0.686 \pm 0.08$ \\
\hline & LSB & $171 \pm 1.3$ & $93.80 \pm 1.5$ & $105.4 \pm 1.5$ & $5.4 \pm 0.2$ & $0.559 \pm 0.04$ \\
\hline & LSA & $39 \pm 0.6$ & $21.50 \pm 0.4$ & $465 \pm 2.2$ & $1.5 \pm 0.1$ & $0.157 \pm 0.01$ \\
\hline Gallic acid $^{c}$ & - & - & $94.31 \pm 0.9$ & $14 \pm 0.2$ & $7.5 \pm 0.1$ & - \\
\hline
\end{tabular}

${ }^{\mathrm{a}} \mathrm{mg} \mathrm{GAE} / \mathrm{g}$ of extract, ${ }^{\mathrm{b}}$ equivalent to $\mathrm{FeSO}_{4} \cdot 7 \mathrm{H}_{2} \mathrm{O}$, and ${ }^{\mathrm{c}}$ positive control.

antioxidant capacities of components. These chromogens (the violet DPPH radical and the blue green ABTS radical cation) are easy to use, have a high sensitivity, and allow for rapid analysis of the antioxidant activity of a large number of samples. These assays have been applied to determine the antioxidant activity of pure components [12-14]. DPPH has been widely used to evaluate the free radical scavenging effectiveness of various antioxidant substances [15]. In the DPPH assay, the antioxidants were able to reduce the stable radical DPPH to the yellow-colored diphenyl-picrylhydrazyl. The method is based on the reduction of alcoholic DPPH solution in the presence of a hydrogen-donating antioxidant due to the formation of the nonradical form DPPH-H by the reaction. DPPH is usually used as a reagent to evaluate the free radical scavenging activity of antioxidants. DPPH is a stable free radical and accepts an electron or hydrogen radical to become a stable diamagnetic molecule [16].

The radical scavenging ability of extracts was checked by using DPPH as a free radical, and it was noted from results that all extracts of stem bank exerted remarkable antiradical activity and ranged from $45.30 \pm 0.6 \%$ to $94.50 \pm 2.1 \%$, with ethyl acetate extract showing maximum activity as shown in Figure 1. All extracts of leave are very effecteive against DPPH assay, while in seed, $n$-butanol extract $93.80 \pm 1.5 \%$ and n-hexane extract showed $10.40 \pm 0.5 \%$ activity as shown in Figure 1. Ethyl acetate extracts of stem bark and leaves showed the least $\mathrm{IC}_{50}$ values $15.9 \pm 0.5 \mu \mathrm{g}$ and $14.5 \pm 0.8 \mu \mathrm{g}$ with 94.5 \pm 2.1 and $96.30 \pm 0.9 \%$ DPPH inhibition, respectively (Table 1 and Figure 2).

Free radicals such as oxygen, superoxide, and hydroxyl are biologically important substances which are naturally released from human tissues. The highly reactive radicals

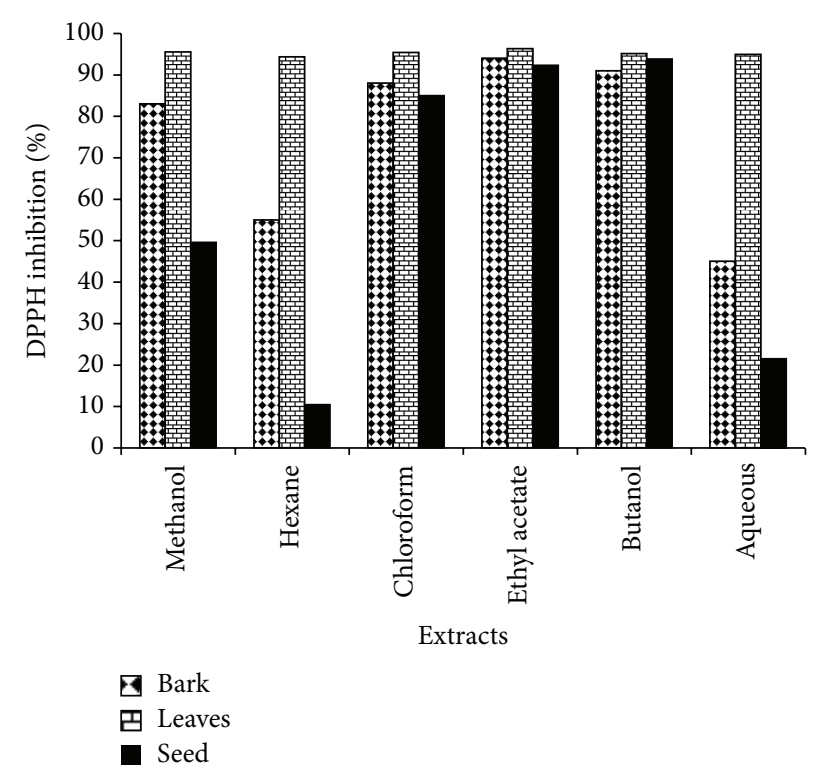

FIGURE 1: DPPH inhibition potential of different extracts of $L$. pulverulentus.

can cause oxidative damage to DNA, lipids, and proteins $[17,18]$. Therefore, free radicals result in many disorders like cancer, cardiovascular diseases, and diabetes mellitus $[19,20]$. Flavonoid and phenolic compounds and the plant extracts rich in these two type of compounds exhibit significant free radical scavenging activity and antioxidant activity. The method of DPPH free radical scavenging can be used to 


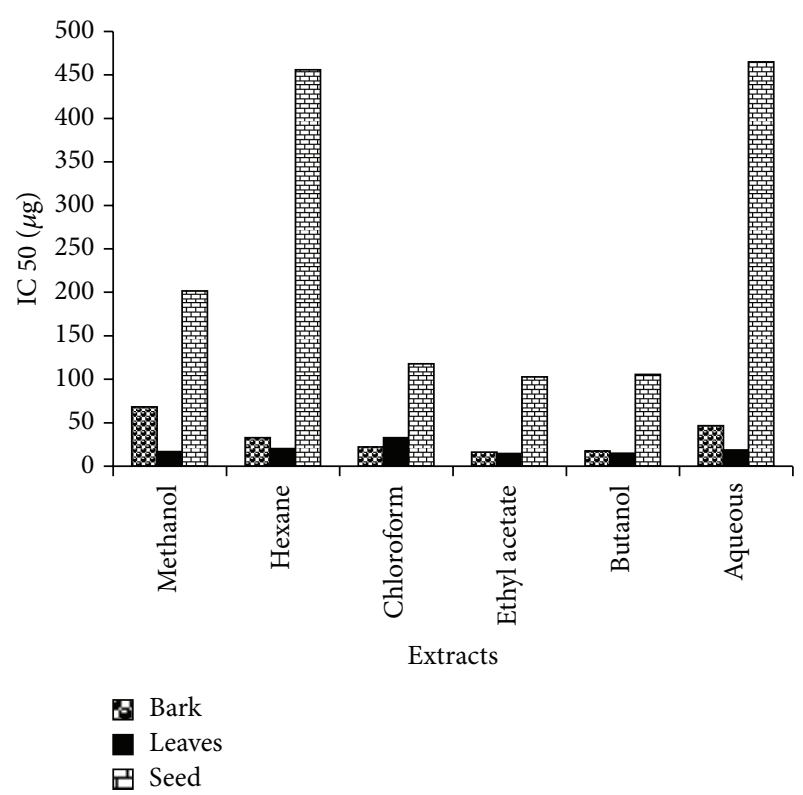

FIGURE 2: $\mathrm{IC}_{50} \mu \mathrm{g}$ values of different extracts of $L$. pulverulentus.

evaluate the antioxidant activity of specific compounds or extracts. Phenolic compounds are the principal antioxidant constituents of natural products and are composed of phenolic acids and flavonoids, which are potent radical terminators [21] by donating hydrogen to radicals. The high potential of polyphenols to scavenge free radicals may be because of their hydroxyl groups [22]. DPPH forms a stable molecule on accepting an electron or a hydrogen atom and thus has applications in the determination of radical scavenging activity of natural products $[23,24]$.

The reducing power of the extracts was determined using standard protocols such as FRAP and phosphomolybdate assays. All extracts showed remarkable reducing behavior, and it was deduced from the results that ethyl acetate extract of all the three plant parts exhibited the highest activities in the two antioxidant assays: FRAP $(7.7 \pm 0.6,7.5 \pm 0.7$, and $6.6 \pm 0.7 \%$, resp.) and total antioxidant activity $(0.952 \pm 0.09$, $1.190 \pm 0.09$, and $0.686 \pm 0.08$, resp.) as shown in Table 1 and Figure 3. FRAP and total antioxidant activity were measured at different concentrations of extract to check the dose effect on the activities. It was observed from results that both assays are concentration dependent (increasing the concentration of the extract enhanced the ability to reduce the ferric and molybdenum ion).

The correlation studies between total phenols and DPPH as well as FRAP and total antioxidant revealed a strong correlation between phenolics and antioxidant activities of the stem bark, leaves, and seed extracts of $L$. pulverulentus with $R^{2}=0.9506$ (stem bark), 0.8413 (leaves), and 0.8658 (seeds) for DPPH, 0.8185 (stem bark), 0.8648 (leaves), and 0.9131 (seeds) for total antioxidant, and 0.9951 (stem bark), 0.6728 (leaves), and 0.991 (seeds) for FRAP as shown in Figures 4, 5, 6, 7, 8, 9, 10, 11, and 12 .

Several studies have been conducted in the past that natural antioxidants in medicinal and dietary plants were

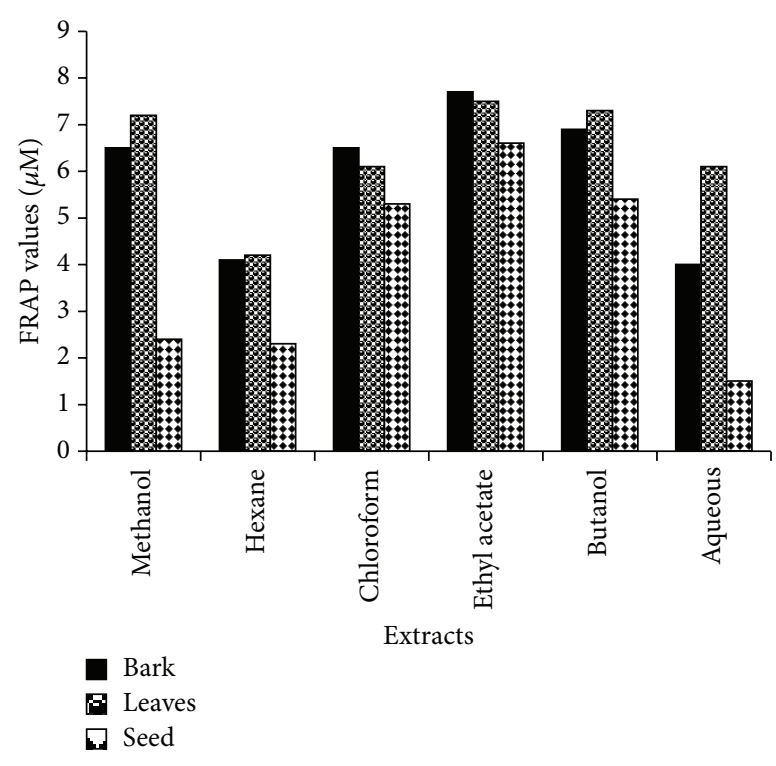

FIGURE 3: FRAP of different extracts of L. pulverulentus.

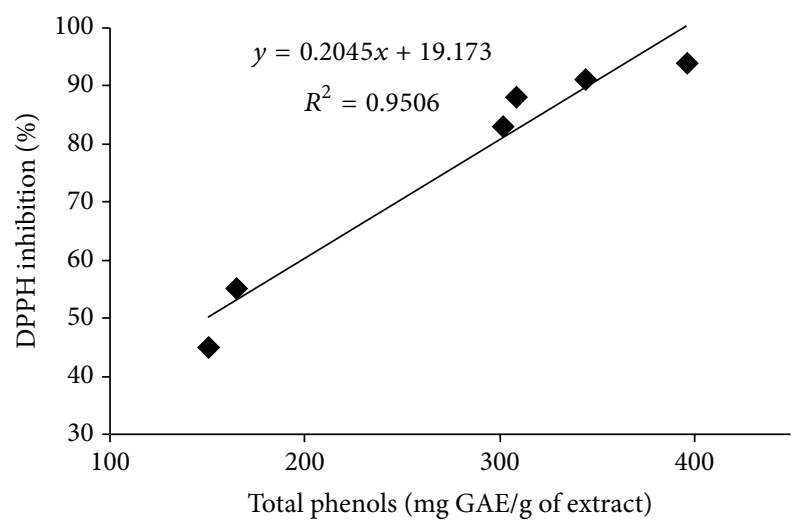

FIGURE 4: Correlation between total phenols and DPPH scavenging activity of bark extracts of Loranthus pulverulentus.

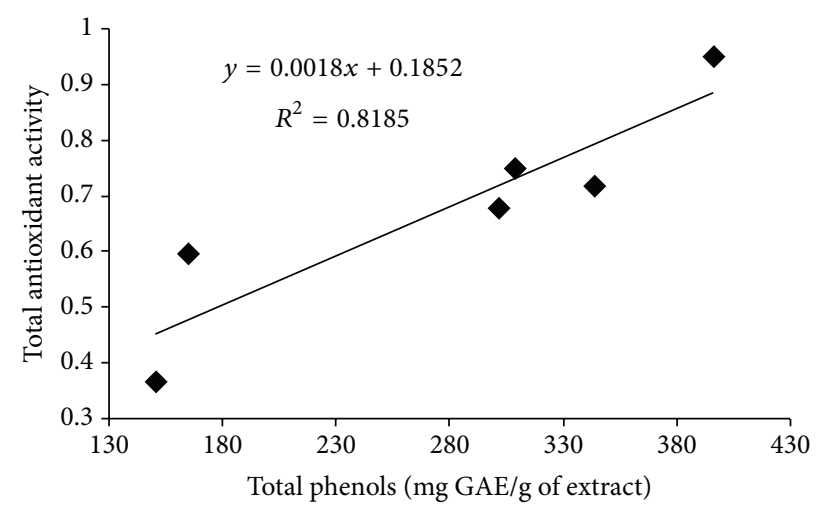

FIGURE 5: Correlation between total phenols and total antioxidant activity of bark extracts of Loranthus pulverulentus. 


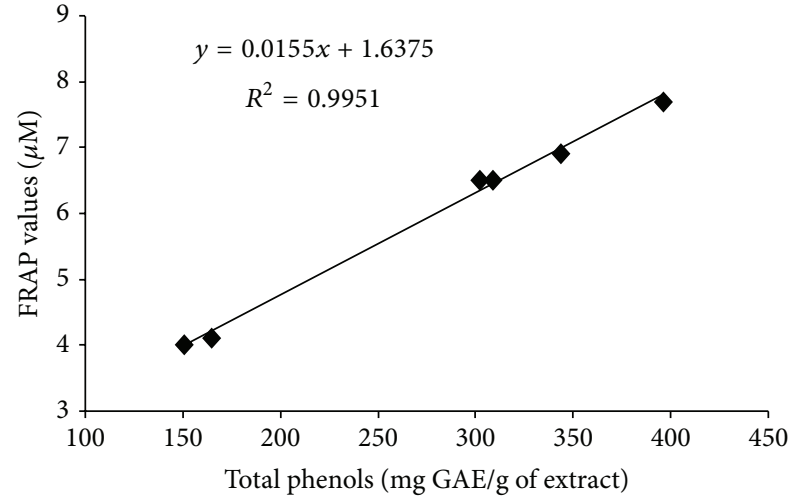

FIgURE 6: Correlation between total phenols and FRAP of bark extracts of Loranthus pulverulentus.

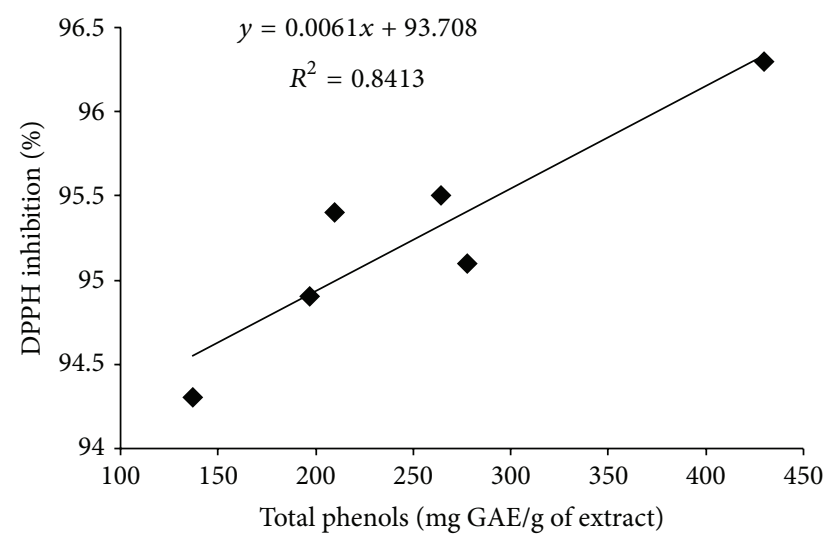

FIGURE 7: Correlation between total phenols and DPPH scavenging activity of leave extracts of Loranthus pulverulentus.

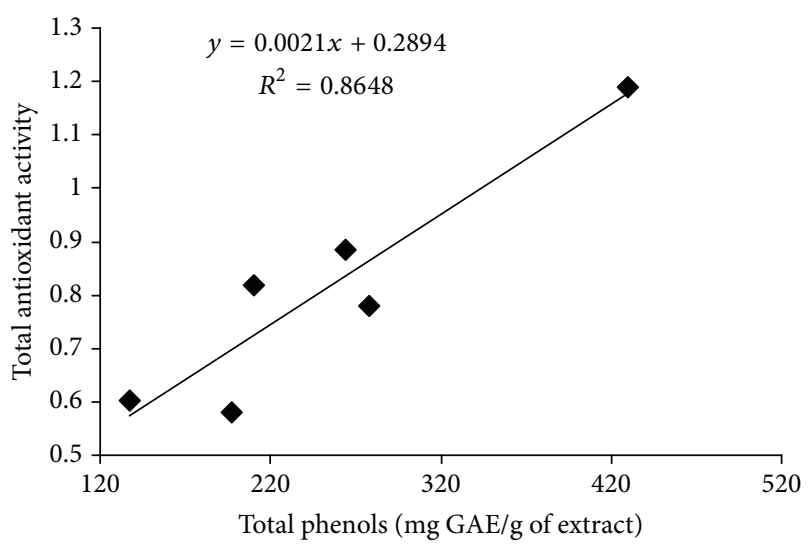

FIGURE 8: Correlation between total phenols and total antioxidant activity of leave extracts of Loranthus pulverulentus.

closely related to their biofunctionalities, such as the prevention or suppression of aging and many diseases associated with oxidative stress: cancer, cardiovascular diseases, rheumatoid arthritis, autoimmune diseases, and AIDS. Thus, antioxidant capacity is widely used as a parameter to characterize food or medicinal plants. Phenolic compounds have

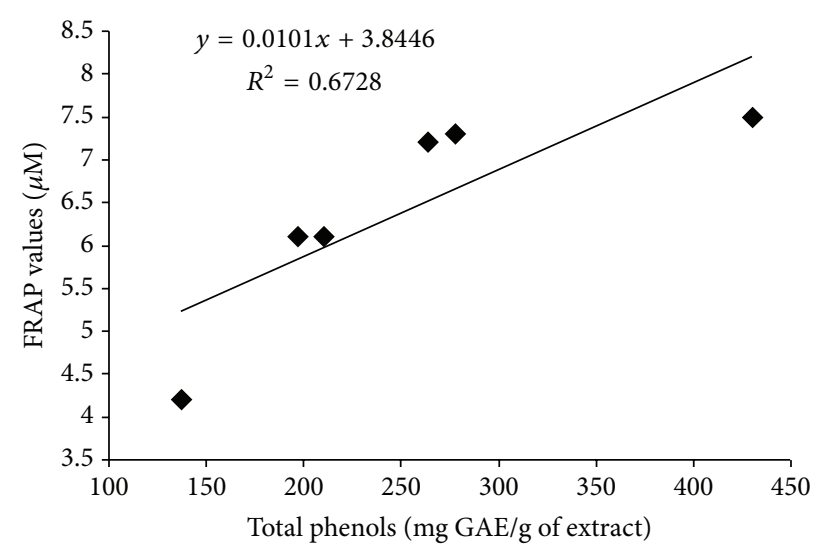

FIGURE 9: Correlation between total phenols and FRAP of leave extracts of Loranthus pulverulentus.

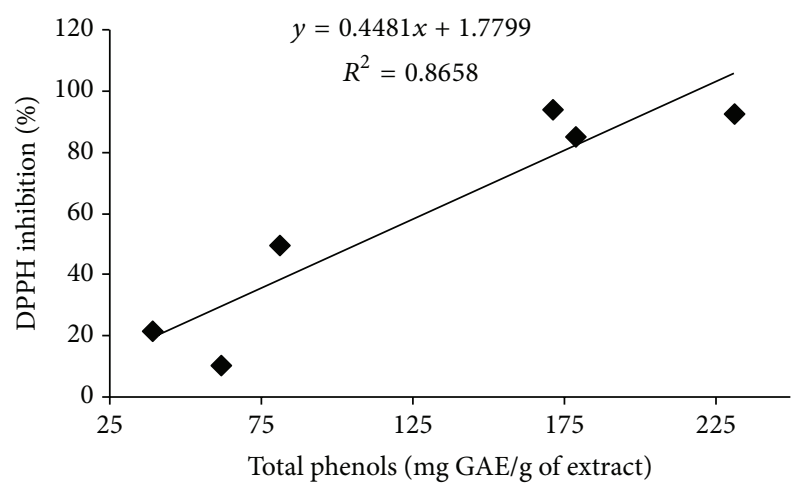

FIGURE 10: Correlation between total phenols and DPPH scavenging activity of seed extracts of Loranthus pulverulentus.

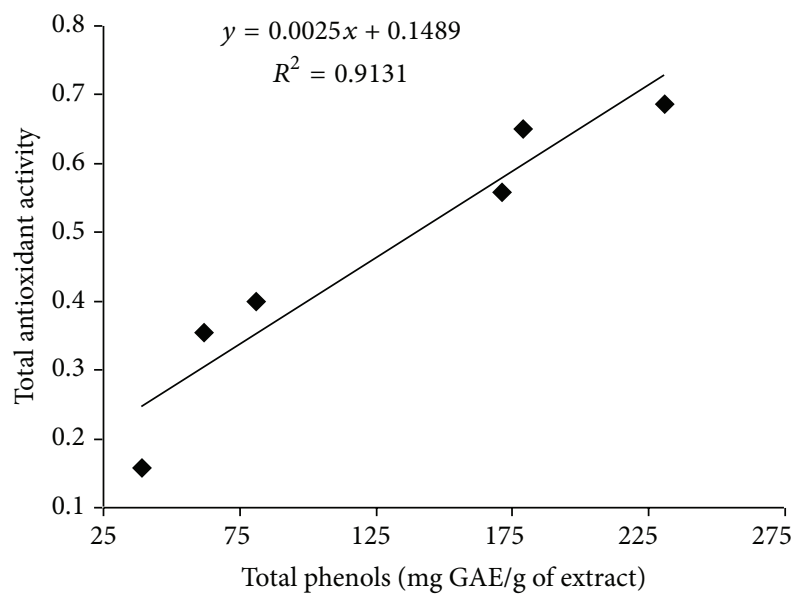

FIGURE 11: Correlation between total phenols and total antioxidant activity of seed extracts of Loranthus pulverulentus.

antioxidant properties because of their ability to scavenge free radicals and active oxygen species such as singlet oxygen and hydroxyl radicals [25]. The compounds responsible for such antioxidants activity can be isolated and then used as antioxidants for the prevention and treatment of free radicalrelated disorders [26-28]. Therefore, research to identify 


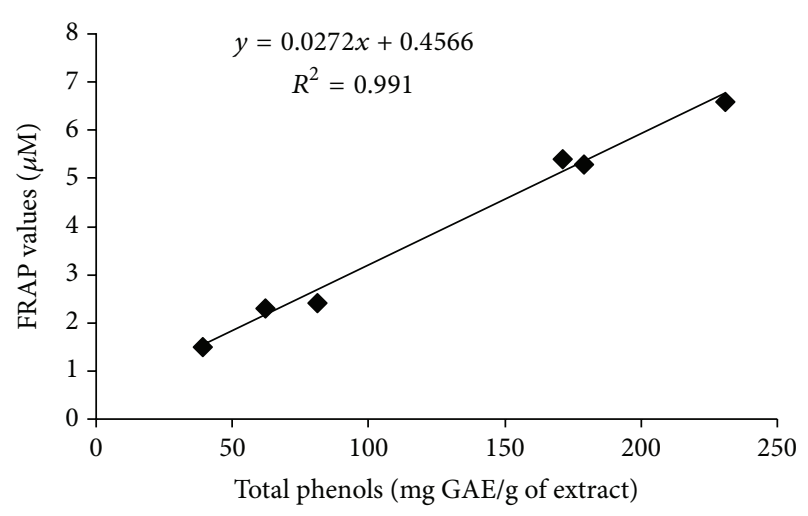

FIGURE 12: Correlation between total phenols and FRAP of seed extracts of Loranthus pulverulentus.

antioxidative compounds is an important issue. Although it remains unclear which of the compounds of medicinal plants are the active ones, polyphenols recently have received increasing attention because of some interesting new findings regarding their biological activities. From pharmacological and therapeutic points of view, the antioxidant properties of polyphenols, such as free radical scavenging and inhibition of lipid peroxidation, are the most crucial. Even though a variety of herbs are known to be sources of phenolic compounds, studies isolating polyphenols and evaluating their antioxidative effects have rarely been carried out.

\section{Conclusion}

It is well known that free radicals are the principal cause of several diseases, including Parkinson's disease, coronary heart disease, cancer, and Alzheimer's disease. This study demonstrated that Loranthus pulverulentus has high phenolic contents and excellent antioxidant activity. It would be interesting to further investigate the potential effectiveness of this plant for treating diseases caused by the overproduction of free radicals.

\section{Acknowledgment}

The authors are grateful to the Higher Education Commission, Pakistan, for financial support.

\section{References}

[1] C. M. Cotton, Ethnobotany: Principals and Applications, John Wiley \& Sons, Chichister, UK, 1996.

[2] J. Buckingham, Dictionary of Natural Compounds, Chapman and Hall, london, UK, 1999.

[3] A. Djeridane, M. Yousfi, B. Nadjemi, D. Boutassouna, P. Stocker, and N. Vidal, "Antioxidant activity of some algerian medicinal plants extracts containing phenolic compounds," Food Chemistry, vol. 97, no. 4, pp. 654-660, 2006.

[4] A. Azzi, K. J. A. Davies, and F. Kelly, "Free radical biologyterminology and critical thinking," FEBS Letters, vol. 558, no. 1-3, pp. 3-6, 2004.
[5] B. Barlow, "Provisional key to the genera of Loranthaceae and Viscaceae of the flora Malesiana region," Flora Malesiana Bulletin, vol. 10, pp. 335-338, 1991.

[6] R. K.-Y. Zee-Cheng, "Anticancer research on Loranthaceae plants," Drugs of the Future, vol. 22, no. 5, pp. 519-530, 1997.

[7] M. Ajaib, Z.-U. Khan, N. Khan, and M. Wahab, "Ethnobotanical studies on useful shrubs of district Kotli, Azad Jammu \& Kashmir, Pakistan," Pakistan Journal of Botany, vol. 42, no. 3, pp. 1407-1415, 2010.

[8] S. G. Khattak, S. N. Gilani, and M. Ikram, "Antipyretic studies on some indigenous Pakistani medicinal plants," Journal of Ethnopharmacology, vol. 14, no. 1, pp. 45-51, 1985.

[9] D. Shahwar, S.-U. Shafiq-ur-Rehman, N. Ahmad, S. Ullah, and M. A. Raza, "Antioxidant activities of the selected plants from the family Euphorbiaceae, Lauraceae, Malvaceae and Balsaminaceae," African Journal of Biotechnology, vol. 9, no. 7, pp. 1086-1096, 2010.

[10] D. Shahwar, S. U. Rehman, and M. A. Raza, "Acetyl cholinesterase inhibition potential and antioxidant activities of ferulic acid isolated from Impatiens bicolor Linn," Journal of Medicinal Plant Research, vol. 4, no. 3, pp. 260-266, 2010.

[11] A. B. Aliyu, H. Ibrahim, A. M. Musa, M. A. Ibrahim, A. O. Oyewale, and J. O. Amupitan, "In vitro evaluation of antioxidant activity of Anisopus mannii N.E. Br," African Journal of Biotechnology, vol. 9, no. 16, pp. 2437-2441, 2010.

[12] J. M. Awika, L. W. Rooney, X. Wu, R. L. Prior, and L. CisnerosZevallos, "Screening methods to measure antioxidant activity of Sorghum (Sorghum bicolor) and Sorghum products," Journal of Agricultural and Food Chemistry, vol. 51, no. 23, pp. 6657-6662, 2003.

[13] L. Yu, S. Haley, J. Perret, M. Harris, J. Wilson, and M. Qian, "Free radical scavenging properties of wheat extracts," Journal of Agricultural and Food Chemistry, vol. 50, no. 6, pp. 1619-1624, 2002.

[14] R. Van den Berg, G. R. M. M. Haenen, H. van den Berg, W. van der Vijgh, and A. Bast, "The predictive value of the antioxidant capacity of structurally related flavonoids using the trolox equivalent antioxidant capacity (TEAC) assay," Food Chemistry, vol. 70, no. 3, pp. 391-395, 2000.

[15] B. Özcelik, J. H. Lee, and D. B. Min, "Effects of light, oxygen and $\mathrm{pH}$ on the 2, 2-diphenyl-1-picrylhydrazyl (DPPH) method to evaluate antioxidants," Journal Agricultural and Food Chemistry, vol. 68, pp. 487-490, 2003.

[16] J. R. Soares, T. C. P. Dinis, A. P. Cunha, and L. M. Almeida, "Antioxidant activities of some extracts of Thymus zygis," Free Radical Research, vol. 26, no. 5, pp. 469-478, 1997.

[17] A. D. Boveris, M. Galleano, and S. Puntarulo, "In vivo supplementation with Ginkgo biloba protects membranes against lipid peroxidation," Phytotherapy Research, vol. 21, no. 8, pp. 735-740, 2007.

[18] K. L. Fritz, C. M. Seppanen, M. S. Kurzer, and A. Csallany Saari, "The in vivo antioxidant activity of soybean isoflavones in human subjects," Nutrition Research, vol. 23, no. 4, pp. 479487, 2003.

[19] Y. S. Velioglu, G. Mazza, L. Gao, and B. D. Oomah, "Antioxidant activity and total phenolics in selected fruits, vegetables, and grain products," Journal of Agricultural and Food Chemistry, vol. 46, no. 10, pp. 4113-4117, 1998.

[20] J. Vaya and M. Aviram, "Nutritional antioxidants mechanisms of action, analysis of activities and medical applications," Current Medicinal Chemistry, vol. 1, pp. 99-117, 2001. 
[21] D. Amić, D. Davidović-Amić, D. Bešlo, V. Rastija, B. Lučić, and N. Trinajstić, "SAR and QSAR of the antioxidant activity of flavonoids," Current Medicinal Chemistry, vol. 14, no. 7, pp. 827845, 2007.

[22] T. Sawa, M. Nakao, T. Akaike, K. Ono, and H. Maeda, "Alkylperoxyl radical-scavenging activity of various flavonoids and other phenolic compounds: implications for the anti-tumorpromoter effect of vegetables," Journal of Agricultural and Food Chemistry, vol. 47, no. 2, pp. 397-402, 1999.

[23] M. Jun, U. Tohru, L. Jianzhang, and F. Takeshi, "Identification and evaluation of antioxidant activities of bamboo extracts," Forestry Studies in China, vol. 6, pp. 1-5, 2004.

[24] G. C. Yen and H. Y. Chen, "Antioxidant activity of various tea extracts in relation to their antimutagenicit," Journal Agricultural and Food Chemistry, vol. 46, pp. 849-854, 1995.

[25] O. Erol-Dayi, M. Pekmez, M. Bona, A. Aras-Perk, and N. Arda, "Total phenolic contents, antioxidant activities and cytotoxicity of three Centaurea species: C. calcitrapa subsp. calcitrapa, C. ptosimopappa and C. spicata," Free Radical Antioxidant, vol. 1, pp. 31-36, 2011.

[26] E. Middleton Jr., C. Kandaswami, and T. C. Theoharides, “The effects of plant flavonoids on mammalian cells: implications for inflammation, heart disease, and cancer," Pharmacological Reviews, vol. 52, no. 4, pp. 673-751, 2000.

[27] L. Packer, G. Rimbach, and F. Virgili, "Antioxidant activity and biologic properties of a procyanidin-rich extract from pine (Pinus maritima) bark, pycnogenol," Free Radical Biology and Medicine, vol. 27, no. 5-6, pp. 704-724, 1999.

[28] J. Vaya and M. Aviram, "Nutritional antioxidants mechanisms of action, analysis of activities and medical applications," Current Medicinal Chemistry, vol. 1, no. 1, pp. 99-117, 2001. 


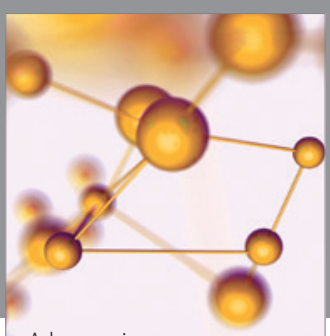

Physical Chemistry
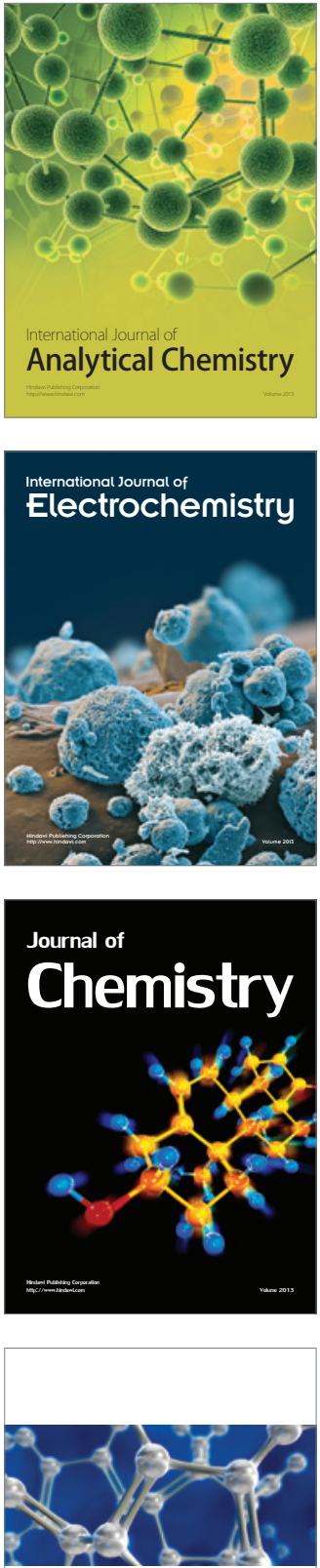

ISRN

Inorganic Chemistry

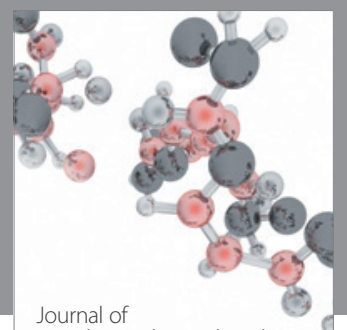

Analytical Methods in Chemistry

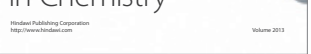

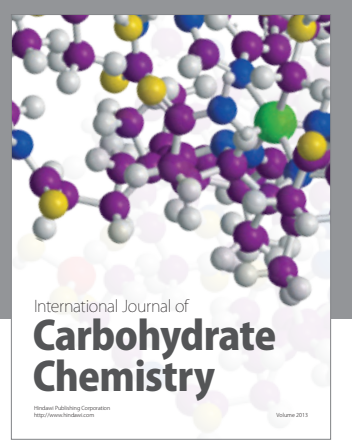
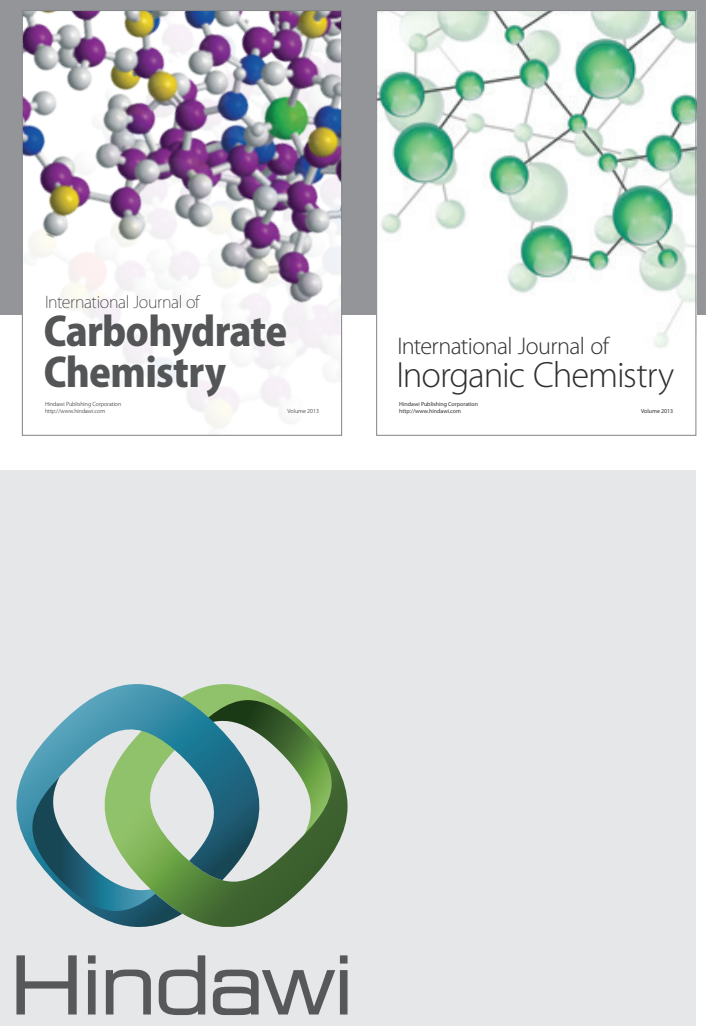

Submit your manuscripts at http://www.hindawi.com
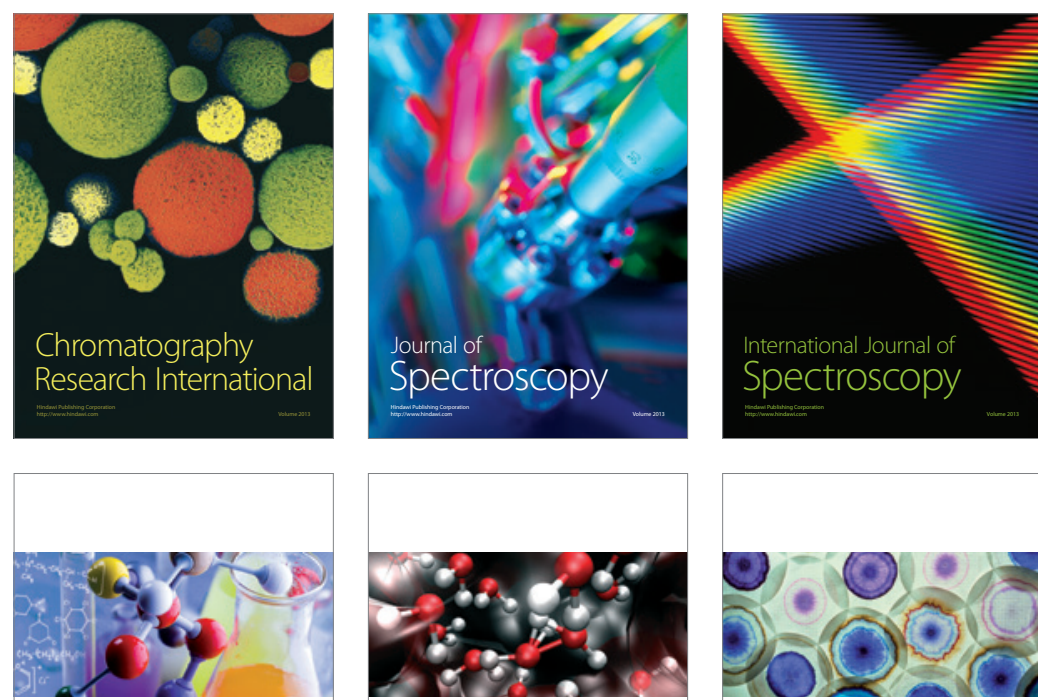

ISRN

ISRN

Organic Chemistry

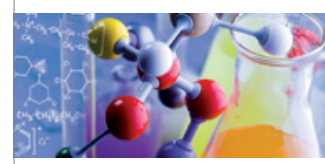

Physical Chemistry

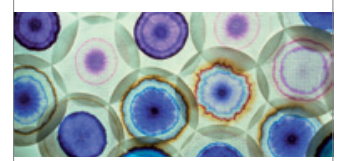

ISRN

Chromatography

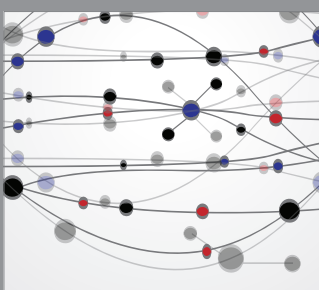

The Scientific World Journal
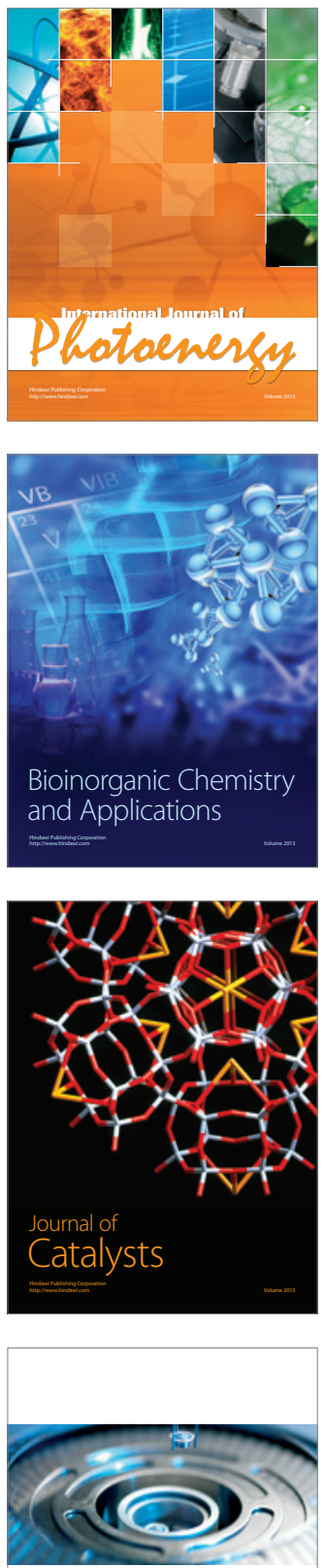

ISRN

Analytical

Chemistry 


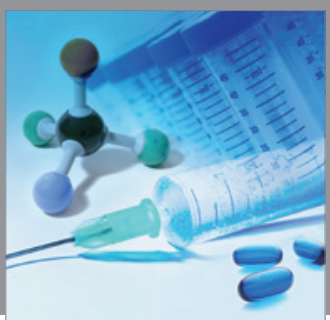

International Journal of

Medicinal Chemistry

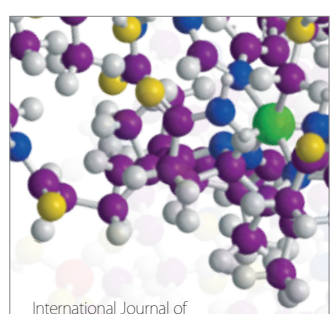

Carbohydrate Chemistry

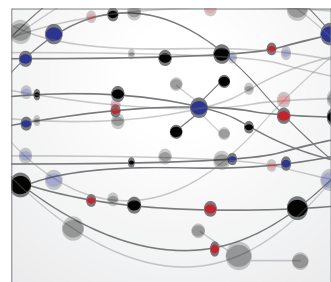

The Scientific World Journal
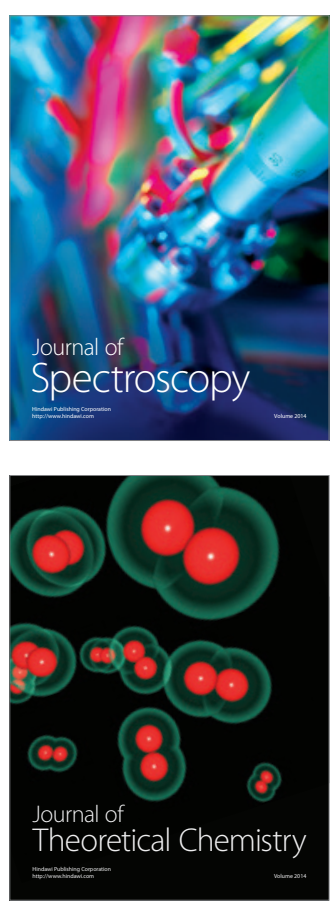
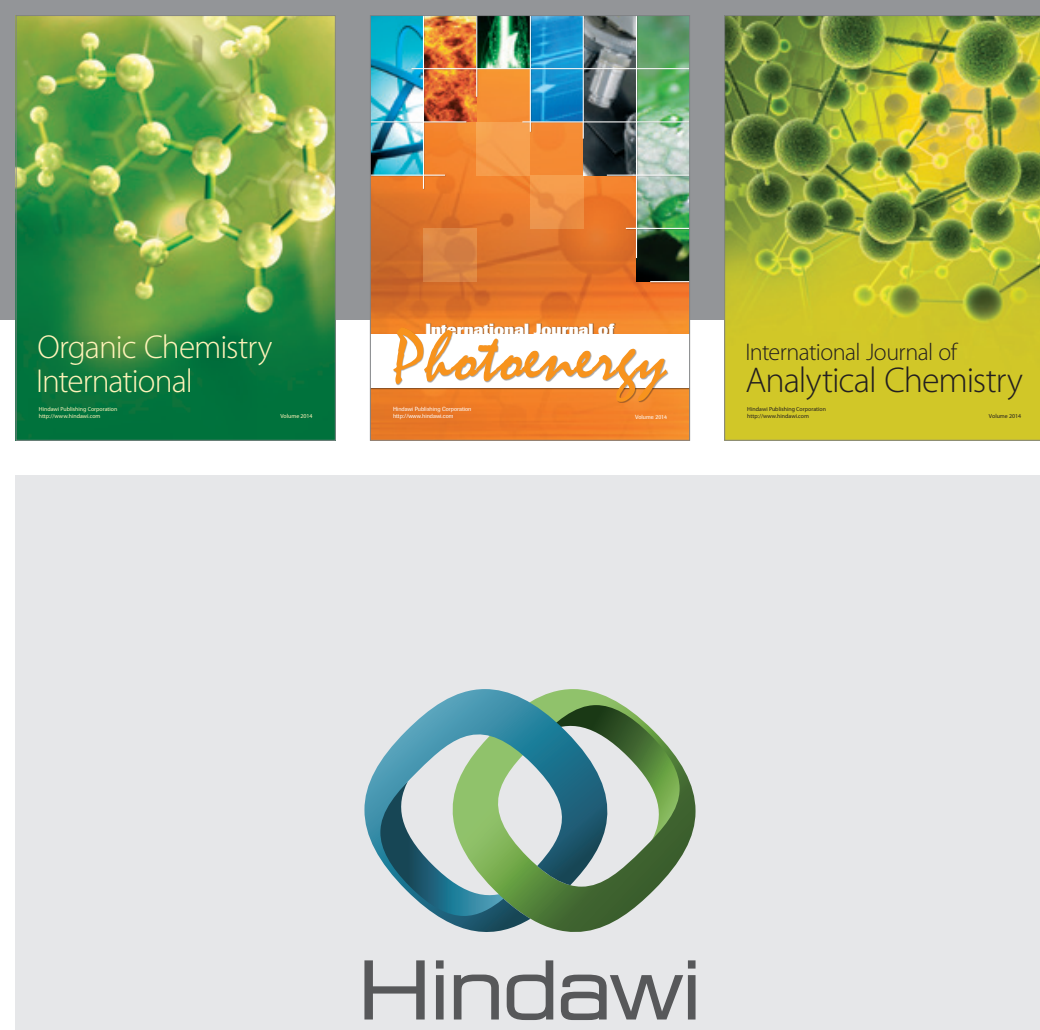

Submit your manuscripts at

http://www.hindawi.com
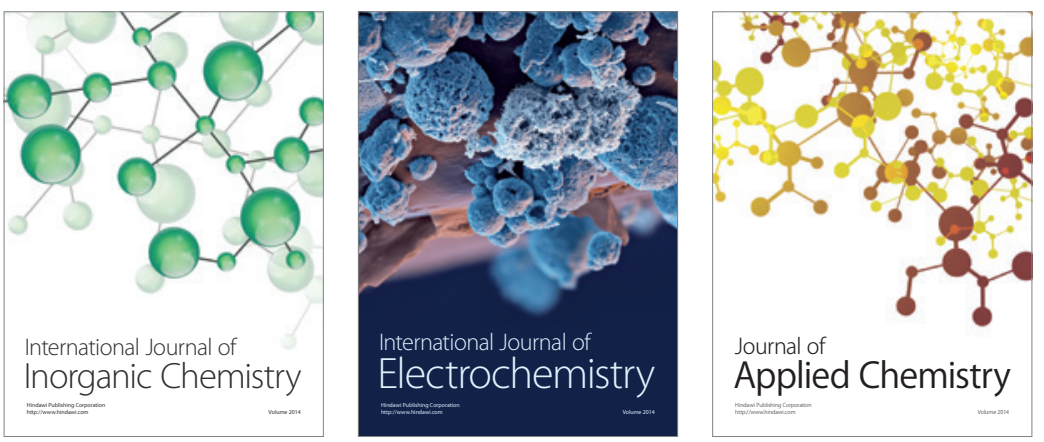

Journal of

Applied Chemistry
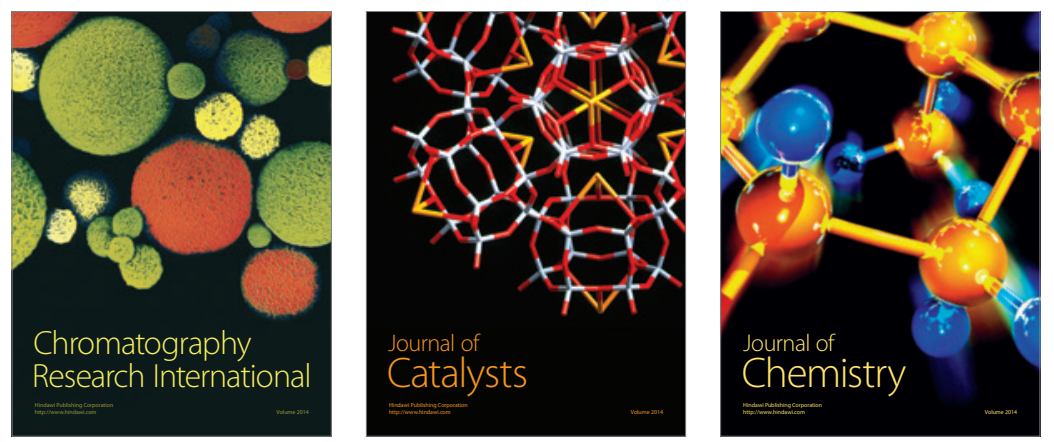
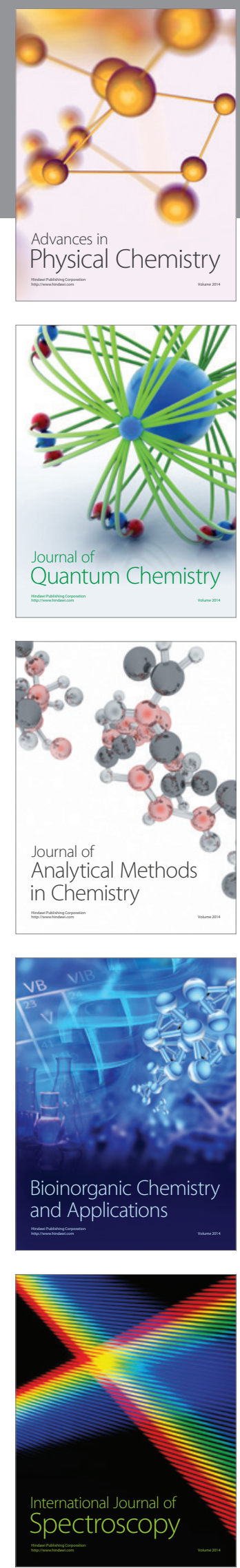